\title{
Negotiating the EU Data Protection Reform: Reflections on the Household Exemption
}

\author{
Napoleon E. Xanthoulis* \\ Attorney at Law \\ LLB (Honours) UCL; BA, MSc Panteion University \\ 24-16 Larnakos av., Apart. 502, 1035 Pallouriotissa, Nicosia, Cyprus \\ napoleon.xanthoulis.09@ucl.ac.uk
}

\begin{abstract}
The re-drafting of the 'household exemption' comprises one of the main areas of dispute in the course of the ongoing negotiations of the EU data protection reform. The aim of this paper is twofold: First, we present and critically assess the wording proposals that have been put forward mainly at EU institutional level and identify the particular areas which cause tension. Second, we concomitantly ask which is the most appropriate wording for the exemption in question and in particular, whether the household exemption should comprise of a set of decisive criteria or whether it should provide a more general framework. We eventually argue for a broad wording of the Article 2(2)(d) coupled with the addition of further non-determinative criteria at Recital 15, i.e. the non-normative part of the proposed Regulation.
\end{abstract}

Keywords: Personal data; Household exemption; EU data protection reform; General Data Protection Regulation; Data processing; Data controllers; User-generated content

\section{Introduction}

The European Commission ('EC') Vice President Vivian Reding's decision to initiate a review of the current EU data protection legal framework, in January 2012, has as expected dominated the broader legal debate on privacy and personal data protection within the European Union ('EU') and beyond. The proposed General Data Protection Regulation (the 'Proposed Regulation'), which aims to replace the existing EU legal framework, has been the subject of extensive negotiations at EU inter-institutional level and generated a strong debate between the concerned stakeholders, such as Internet Service Providers ('ISPs') and online users representatives.

In this regard, a major area of dispute comprises a particular issue related to the limitation of the scope of the proposed Regulation, namely the so-called 'household exemption'. The said exemption has received a surprisingly lack of scholarly attention, despite its significance, namely that it practically draws the border lines of the application of the proposed Regulation by defining the type of activities which may fall under its provisions, contrary to ones that are considered part of a person's private life.

\footnotetext{
* The author would like to express his gratitude to Dr. K. Chrysostomides \& Co LLC for the continuous support and to Miss Helen Ayres for her valuable comments on earlier drafts of this paper. Needless to say, responsibility for any errors or omissions remains with the author.
} 
In the past, the definition and application of the household exemption might have seemed an easy task; in the WEB 2.0 era it constitutes a complicated and fragile puzzle. Wong and Savirimuthu (2008) argue that today individuals have a range of new technologies for accessing media and sharing information, while at the same time increased connectivity has maximised individuals' exposure and immersion to information. Apparently, as individuals spend more time in the social spaces, we can detect a shift in cultural attitudes towards space, information, identity and privacy. To put it simply, determining when a person acts in his personal or household capacity instead being active in the public sphere is much harder to define.

The aim of this paper is twofold: First, to ask what is the current stage of negotiations at EU level with regard to reforming the household exemption. In particular, we focus on presenting and critically assessing the wording proposals made in the course of the negotiation process and identify the particular areas of tension. Second, to ask what is the most appropriate wording for the exemption in question. To achieve this, we analyse the most prevailing proposals and we categorise them into two general schools of thought. We then re-formulate our question: What are the benefits and disadvantages of selecting a wording that comprises a set of decisive criteria on the one hand, or provides for a more general framework, leaving more space for flexibility, on the other. Finally, we present our own view which contains, inter alia, elements from both of the abovementioned perspectives.

We structure the paper as follows: First, we present an overview of the current stage of negotiations on the data protection reform at EU level. Second, we critically discuss the current application of the household exemption, with reference to the wording of Directive 95/46/EC and the relevant Court of Justice of the European Union ('CJEU') jurisprudence. In this context, we identify the main points of criticism which raised the need to re-draft the household exemption provision. Third, we place the problematique of household exemption in the Web 2.0 context to show the interrelation between household exemption and the notion of data controller. We focus on how the processing of data within Social Networking Sites ('SNS') and the the use of User-Generated Content ('UGC') blur the distinction between data subjects and data controllers and its implications. Fourth, we discuss, from a critical perspective, three suggested criteria in determining the application of the household exemption, in the context of the proposed Regulation and identify each one's defects. Finally, we argue for an alternative option, namely, to provide a general application framework within the normative part of the proposed Regulation and include several non-determinative criteria at the respective Recital.

In our paper, we conduct a legal analysis in the course of which we undertake a review of primary sources, such as the proposed legislation, internal EU institutional documents and EU organ's recommendations and reports as well as secondary sources, including the relevant academic literature and proposals published by concerned private third parties and national competent authorities. We hope that our analysis will contribute to the EU data protection reform literature and assist in explaining why the debate on the household exemption constitution has raised further concerns on the proposed Regulation in terms of controversial wording, potential ineffectiveness, and for providing an imbalance of the affected rights and interests. 


\section{Negotiating the Reform: Where do we stand?}

The reform package comprises two legislative proposals based on Article 16 TFEU, the new legal basis for data protection measures introduced by the Lisbon Treaty. The first proposal constitutes a General Data Protection Regulation which aims to replace the existing Data Protection Directive 95/46/EC (Lostarakou, 2013). The second is a Directive of the European Parliament and the Council on data protection in the field of police and judicial cooperation in criminal matters which intends to replace the Framework Decision 2008/977/JHA. This paper only discusses the application of the proposed Regulation.

The Draft Regulation is currently debated under the ordinary legislative process, which gives equal weight to both the European Parliament ('EP') and the Council of the European Union (the 'Council') by requiring a broad consensus in order to become law. Since January 2012, when the EC first published its proposed Regulation, it has been the subject of intense negotiations, re-drafts and controversial criticism. A striking example of the atmosphere that characterises the on-going debate within the EP is that over 3,000 amendments have been put forth by the members of the Civil Liberties, Justice and Home Affairs Committee ('LIBE'), the latter are currently preparing a compromising text for an EP plenary session vote. As a next step, once their respective internal positions are prepared, the EP and the Council will have to engage into inter-institutional negotiations on the finalized text (Hunton \& Williams, 2013).

As far as the Council is concerned, at the end of May 2013, the Presidency published a compromised text of the EC's original proposal. It also pointed out that several member states, still had reservations on the choice of legal form of the proposed instrument and would perhaps prefer to agree for a Directive. Whilst at the same time acknowledging that substantial progress has been achieved during the negotiations of the Proposed Regulation, it considered necessary to note that the approach of the member states is a: "conditional one in the sense that no part of the draft Regulation can at this stage be finally agreed until the whole text of the Regulation is agreed" (Council, 10227/13). Overall, the Council is still to reach a final agreement on several issues including, inter alia, the legal form of the reform, the notion of consent, the risk-based approach, the extension of the scope to cover EU institutions, agencies and bodies and the EC's potential power to legislate further, in the form of delegated and implemented acts.

The legislative process is planned to be concluded by mid-2014 and the Regulation would be expected to come into force after two years, although significant delays raise doubts on the compliance with such an optimistic schedule. If both the EP and the Council agree to their respective internal positions by the end of 2013, this would give approximately three months for inter-institutional negotiations. Assuming the latter are completed on time, the EP's would then have chance to vote on the negotiated position before the last plenary session in April 2004, i.e. before the next EP elections (IAB, 2013). If all goes well, the proposed Regulation is expected, according to the optimistic scenario, to come into force sometime in 2016. 


\section{The Household Exemption: Current Legal Framework}

\section{(a) Article 3(2) of Directive 95/46/EC}

The Directive 95/46/EC (the 'Directive'), currently in force, contains a number of exceptions and exemptions, some of them being of general application and others limited to specific parts. The so called "household exemption", under Article 3(2) of the Directive, to which this paper focuses, comprises an exemption of general application, (Hunton \& Williams, 2012) providing that the Directive shall not apply to the processing of personal data: "by a natural person in the course of a purely personal or household activity". In other words, where the exemption applies, the provisions of the Regulation have no effect.

The underlying justification for introducing the household exemption can be approached both from constitutional, or human rights protection, and regulatory perspectives. As Wong and Savirimuthu (2008) suggest, on the one hand, "any encroachment in to the private social spaces would be seen as unjustified and contrary to the prevailing social norms and values" (in other words, as a violation of the right to privacy), while on the other hand, "at a regulatory level, it is not feasible for the State or its enforcement authorities to secure compliance with the obligations".

The Directive's current wording arguably raises more questions rather than providing clear answers. How shall the personal and household activities be defined? Is there an essential conceptual difference between personal and household types of activities? How do we differentiate a purely personal act from a mere personal one? In sum, what criteria shall we apply in deciding whether certain activities of data processing fall under the abovementioned exemption and how are these criteria defined?

Despite its importance and the fact that the said provision, as well as the remaining essential principles of the Directive, have been implemented in most of the national laws of the EU member states, (Mitrou, 2010b) with minor unimportant variations, (EC, 2010:8) the application of the household exemption had apparently attracted little or no attention, at least until recently.

In fact, these questions became essential as the unlimited access to internet and the more functional and sophisticated information and communication technologies (ICT) opened the way for a range of personal processing activities that the current Directive could not have been expected to anticipate (Art. 29WP, 2013:2). Individuals today run their own websites and blogs, use social networks, sell items on e-commerce websites, take part in online petition campaigns and share geo-location data with others. As a result, both adults and minors are now able to make personal data about themselves or others available worldwide, to anyone, instantly (Art. 29WP, 2013:2-3).

Defining in binary terms, what is personal from what is not, or in essence, what belongs to someone's private life from what extends to the public sphere often seems an impossible task. However, "[t]he amount of everyday activity that until recently 
took place away from the computer but is now transferred online, legitimizes the need for the law to reflect the variety of online behaviors" (Warso, 2013:492).

\section{(b) The Linqvist Decision}

The CJEU has tried to provide some guidance in this regard, in an effort to limit the acknowledged vagueness of Article 3(2) of the Directive and answer the questions surrounding the application of the household exemption.

The leading authority in this respect is the CJEU's decision in the Linqvist case. Mrs Linqvist, a Swedish national, was prosecuted for failing to comply with the data protection laws, following the posting of information relating, inter alia, to her work colleagues on her webpage, without prior obtaining their consent. The national court referred six questions to the CJEU for a preliminary ruling, one of them being whether the act of loading information of this type onto a private home page, which is nonetheless, accessible to anyone who knows its address, could be regarded as falling outside the scope of the Data Protection Directive on the ground that it is covered by one of the exemptions in Article 3(2). The CJEU held inter alia, the following: "[The] exception must therefore be interpreted as relating only to activities which are carried out in the course of private or family life of individuals, which is clearly not the case with the processing of personal data consisting in publication on the internet so that those data are made accessible to an indefinite number of people"(paragraph 47).

Furthermore, the CJEU in Linqvist was of the opinion that the balancing of the concerned interests was a task for the national court. Here, Mrs Lindqvist's freedom of expression had to be "weighted against the protection of the private life of the individuals about whom Mrs Linqvist has placed data on her Internet site"(paragraph 86).

In this regard, the CJEU seems to be suggesting that, where certain data can be subject to unlimited access, this would result in the act being regarded as falling within the scope of the Directive, thus outside the personal/household sphere. In other words, unlimited access can constitute a (determinative?) criterion towards deciding that the household exemption shall not apply. At the same time, it is noted that the CJEU left open the question how cases, where access is granted to anything close to but less than "access to an indefinite number of people", should be treated.

The Linqvist decision can be perceived as an attempt of the CJEU to essentially define what is private in the internet world. However, as it has been argued, this has the undesirable effect of creating a public/private partition, without however indicating where one may draw the line between private and public purposes (Wong and Savirimuthu, 2008). In addition, it seems to be placing an onus on the individuals to limit access on their webpages if they wanted to be exempted. In other words individuals have to show that the webpage was intended to be used for private purposes; a requirement which is a harder threshold to prove.

Arguably, the decision takes a narrow approach to the scope of the exemption by providing that that it will not apply when the processed information is accessible to everyone. On the one hand, it implies that the exemption would perhaps only cover 
situations where information is accessible only to one's family and friends. On the other, "mere acquaintances or like minded contacts (such as within a group that shares recreational or social concerns) would seem to fall within a grey area, not to mention 'friends' on social networking sites who may not, in fact, be 'real' friends or even acquaintances"(Roth, 2010).

The rule applied in Linqvist was further affirmed by the CJEU in Satamedia, a case where it also held that the activity fell under the scope of the Directive, given than the purpose of the activities of Markkinapörssi and Satamedia, "was to make the data collected accessible to an unrestricted number of people" (paragraph 44).

Despite the CJEU's genuine efforts to provide clarity to the application of the household exemption, the provision in question was still considered as sufficiently vague and ambiguous and attracted reasonable criticism. First, due to its vagueness, it could not provide any assistance in determining whether an act shall fall under the scope of the exemption. Second, it was argued to be too broad, because it could exempt, in practice, activities that should essentially fall in a person's private sphere, such as the ones related to the processing of personal data online and mainly, but not exclusively, within online networks (EP, 2012:32; Art. 29WP (2009:78).

\section{Contextualising the Problematique}

(a) Household Exemption and Data Controllers in Web 2.0: Two Sides of the Same Coin?

One way to illustrate the puzzle is to take a closer look on the application of household exemption in the online world and particularly to activities undertaken within Web 2.0 technologies. Web 2.0 allows users to create and distribute their own UGC, which promotes inter alia sharing through mass social networking channels and facilitates users to eventually construct their public profile. Social networking providers ('SNP') serve as a tool enabling users to create and exchange content and communication (Giannakaki, 2011). This trend has strong foundations as the use of SNS sustains the misleading impression of the existence of a web "community" Wong, 2008b:11) or in other words, of a false "intimacy on the web" (International Working Group, 2008:2), within which information could be kept private. It is this impression that encourages individuals to increasingly share more information with others.

Therefore the question becomes to what extent we are ready to accept the Directive's application to social networking environments and the use of UGC in online platforms? (Garrie, Wong, 2010:168) To answer this question, it is important to illustrate the direct link between the Directive's applicability (the household exemption's applicability) and the notion of "data controller". This is due the fact that if an individual falls under the definition of data controller, then it simultaneously escapes the application of the household exemption and becomes subject to the provisions of the Directive.

Article 2(d) of the Directive provides a broad definition of data controller: "the natural or legal person, public authority, agency or any other body which alone or 
jointly with others determines the purposes and means of the processing of personal data; where the purposes and means of processing are determined by national or Community laws or regulations, the controller or the specific criteria for his nomination may be designated by national or Community law". Put it more simply, the controller becomes primarily responsible for the compliance with data protection obligations and will also be held liable in case of a breach (Giannakaki, 2011). The EC's proposed Regulation endorsed essentially the same definition (see Article 4(5)), although, the Council's compromise text, at the time of writing, omitted the reference to "means" in relation to the processing of data, leaving only the "purpose of processing" as determinative factor.

Arguably, if the definition of Article 2(d) is applied literally, then its scope would not only cover the SNS but the respective users as well, i.e. individuals who post online information taken by the profiles of other users (Wong, 2008b:1). Being qualified as data controllers, individual users would be subject to several obligations imposed by the Directive, including inter alia ensuring that the processing of the information is done in a fair and lawful manner (Article 6(1)(a) and not be excessive (Article $6(1)(c))$ as well as safeguarding specific rights of data subjects under the Directive (see Articles 7, 8 and 10).

In such circumstance, the gateway for escaping the scope of the Directive would be to fall under the scope of other exemptions, such as when the processing is made for journalistic, artistic and literary purposes (Article 9 of the Directive), or for safeguarding public interest values including but not limited to national security, defence and public security, or even the when the processing must be considered lawful as being part of a person's right to freedom of expression (see Article 13(1)). In this respect, it would indeed be quite useful to clarify the scope of these exemptions (Wong 2009:147), as this exercise would assist in drawing the definitional borders of data controllers and therefore of the household exemption as well. Alternatively, in the event that none of the abovementioned exemptions apply, the only defense available for a user who has undertaken the role of data controller would be to show that the individual to whom the personal data in question relate has provided his consent for their processing (e.g. Articles 7(a) and 8(2)(a) of the Directive). However, showing that such consent has been obtained is not without difficulties (Wong, 2009:144). To sum up, even if the household exemption cannot apply in a particular circumstance, users can still rely on the abovementioned exemptions to prevent the application of the Directive's provisions.

The analysis shows that it is becoming increasingly easier for individuals (and not merely organizations) to be brought within the scope of the Directive when within SNS context (Wong, 2008b:2). Put it differently, in many cases the processing of personal data of other users within SNS (i.e. the posting on information about others on facebook) leads individual users to assume the parallel roles of data subject and data controller.

Limiting the scope of the Directive in social networks environment seems to be a far from an easy task. On the one hand, the granting of a full exemption from data protection requirements to any user who uploads materials to the internet as a private individual would lead to easy circumvention of the rules and, in an age of UGC, 
would fundamentally undermine data protection and privacy itself. Taking the opposite view, the full imposition of the law to all such individuals would seem excessive and, because of the sheer numbers, would be largely unenforceable (EC, 2010:8). It may also lead to a flood of court actions on behalf of individuals claiming misuse of their private information by other users on SNS (Wong, 2008b:13). Therefore, where should the line be drawn?

The legislators of the Directive had not anticipated the emerging challenges of Web 2.0 ICT (International Working Group, 2008:2). The new reform builds on the already existing concepts, therefore new conceptualization of old concepts becomes imperative. Not long ago, the Article 29 Data Protection Working Part ('Art. 29WP') suggested the use of certain factors in deciding whether a SNS user does not act in a private context. One of those circumstances would be when the processing information is available to a high number of third party contacts, some of whom the user may not actually know. In other words, if a user takes an informed decision to extend access beyond self-selected 'friends', this would be an indication that the household exception does not apply and thus data controller responsibilities would come into force (Art. 29WP, 2009:6). Second, Art. 29WP suggests that if an SNS user (or an individual acting on a different platform using UGC) acts on behalf of a company or association, or uses the web 2.0 technology mainly as a platform to advance commercial, political or charitable goals, then such activity may extend beyond a purely personal or household activity and thus the household exemption shall not apply. Here, the user appears to assume the full responsibilities of a data controller who is disclosing personal data to another data controller (SNS) and to other third parties (other SNS users or potentially even other data controllers with access to the data) (Art. 29WP, 2009:6). In other words, defining data controllers and the scope of household exemption is likely to be a question of fact (Art. 29WP, 2010:8). The above-mentioned recommendations are being discussed in more detail below in the context of the household exemption's reform.

\section{(b) Identifying Tensions in a Drafting Exercise}

We have shown that in a world where access to Web 2.0 technologies that enable massive data processing is so common, it becomes increasingly more difficult to determine whether processing falls under the said exemption or not, (Mitrou, 2012; Panagopoulou Koutnatzi, 2012; Piskopani, 2009). In this light, it is imperative that the law should provide better criteria for deciding whether or not processing is being done for personal or household purposes. Thus, the following questions emerge: (a) which criteria shall we apply in making this decision and (b) how should we incorporate them into a legal text? As it will be suggested below, the answers to both of these questions are equally important and interrelated.

On the one hand, it is argued that maintaining an equally broad exception for personal or household activity (as is currently provided in the Directive) in the proposed Regulation will pose an increasing risk for data protection (EDRi, 2013:6) as there will be no detailed legal instrument to guarantee the private activity of users in the online world. In other words, we need, according to this view, to determine in an explicit manner specific criteria that would provide a more solid veil of protection to individuals that, despite being active in the virtual world, should still preserve a 
limited privacy sphere. In the opposite view, composing, from the outset, a list of set and potentially decisive criteria might result in providing a too narrow or too broad exemption. Such option is criticized for causing the inclusion of more circumstances than actually intended within the household exemption's scope, while also potentially excluding others that should be eligible to trigger the application of the exemption.

Arguably, the level of prescriptiveness should perhaps be higher in a Regulation than a Directive, as the former is directly applicable and needs no further transposition into member states laws (Council 16525/1/12:6). Although, in principle this is indeed the case, it is, in our view precisely the element of direct applicability which makes the selection of wording more challenging. When a rule comes into force in the form of a Regulation, once it is enacted, there will be limited space for maneuver beyond the literal interpretation.

\section{Reforming the Household Exemption}

Several wording suggestions focus on limiting the scope of the household exemption by providing one or more determinative criteria in deciding whether it shall apply or not, the main ones being the following: (a) gainful interest, (b) commercial/professional purpose and (c) data accessible to an indefinite number of people. We shall discuss each one in turn.

\section{(a) The "Gainful Interest" Criterion}

The original text of the EC's proposed Regulation (2012) provided for a household exemption along the lines of the existing Directive, with significant, however, differences. In particular, Article 2(2)(d) of the original text provided that the Regulation shall not apply to the processing of personal data "by a natural person without any gainful interest in the course of its own exclusively personal or household activity".

Two main points should be made here: First, the new wording introduces the concept of "gainful interest". Second, the EC considered that the previous term "purely" should be replaced with the word "exclusively" to provide more clarity in this regard.

By introducing the criterion of gainful interest, the EC seeks to draw a line between those processing activities which are personal and those which are commercial in nature, in line with the Australian and Canadian data protection tradition (Roth, 2010:537-538).

Since a definition of gainful interest is not provided we seek some guidance from Recital 15 which accompanies Article 2(2)(d), where it is mentioned that: "This Regulation should not apply to processing of personal data by a natural person, which are exclusively personal or domestic [...] and without any gainful interest and thus without any connection with a professional or commercial activity." In this regard, EC seems to treat the notions of "gainful interest" and "professional or commercial activity" as synonymous (BEUC, 2012:10). 
The limitation of the household exemption's scope through the introduction of the gainful interest criterion raises certain concerns. First, the reference to gainful interest might give the wrong in our view) impression that only non-commercial activity can benefit from the exemption (ICO, 2012:4). This becomes more obvious in circumstances where, although the processing of personal data is done for gainful interest, the activity itself can still regarded as private, for instance, the setting up of a website to sell unwanted birthday presents (ICO, 2013:3-4). In this light, the inclusion of gainful interest seems to cover unwanted circumstances of data processing which, in our view, should fall within the scope of the household exemption, thus escaping data controllers' obligations.

\section{(b) The "commercial / professional objective" Criterion}

Notwithstanding, EC's prima facie treatment of "gainful interest" and professional /commercial" objective, as interrelated concepts, it has been argued that the latter serves better as a sole criterion in this respect. (ICO, 2013:3-4). When considering the application of this criterion, we note, first, that some non-gainful activity - such as running an online political campaign - would in this case be regarded as nonpersonal, thus falling under the scope of the Regulation. The paradox is quite obvious as it would be difficult to argue that a political campaign constitutes part of someone's private life. In parallel, we also come across certain cases where although the processing of personal data on behalf of an individual is done in connection to his or her professional activity, such activity should still be benefited from the exemption. Such is the case of a worker who posts to his blog details of his or her day-to-day work life experiences (ICO, 2012:4). In this view, unless the proposed terms are further specified, there is a real risk (similar but broader to the one identified above with regard to "gainful interest") of narrowing or broadening the household exemption unduly, thus resulting, in certain cases, to unfair treatment and violation of someone's right to freedom of expression respectively.

\section{(c) The "access by an indefinite number of people" Criterion}

As mentioned above at paragraph 3(b), the CJEU decided in Linqvist to use the criterion of "unlimited access" in determining the application of the household exemption. Unsurprisingly, the same criterion has also been suggested to be incorporated into the wording of Article 2(2)(d) of the proposed Regulation.

The main rational in this respect is that the Regulation's wording should reflect and be in line with the CJEU's jurisprudence (EDPS, 2012). In deciding whether an activity falls under the public or domestic sector, we should ask whether the information in question can be accessed by an indefinite number of individuals or not. The ultimate aim seems is simply to prevent individuals making data available to several hundreds or even thousands of individuals from automatically falling under the exemption. If no limitation is introduced, then almost all SNS users would fall under the definition of data controller. In the EDPS's own words: "this criterion should be understood as an indication that an indefinite number of contacts shall in principle mean that the household exception does no longer apply" (2012:15). We note, here, (although it shall be discussed in more detail below) that the said criterion, at least as contained in the EDPS's recommendation, is presented as indicative, rather than a determinative. 
This view found subsequent support in the Opinions of the EP's Committee on Legal Affairs and the Committee on the Internal Market and Consumer Protection, which voiced for the inclusion in Article 2(2)(d) of both the criteria of gainful interest (mentioned above) and access of data to an indefinite number of people.

Although it indeed seems reasonable and common practice, both from a normative and practical perspective, to incorporate the CJEU's ratio decidendi in the Regulation's wording, it has been suggested that the incorporation of the abovementioned sole restriction in the normative part of the law would not assist much in this respect. As it has been characteristically stated: "References to data "made accessible to an indefinite number of individuals" gives rise to questions such as: what circumstances should determine whether the circle of potential recipients of such data is "definite" or "indefinite", in particular whether any significance should be given to the nature of profiles on social networks ("private" or "public" profiles") or to some other circumstances?" (EP, 2012:33).

The abovementioned concerns were recently debated extensively within the EP's LIBE Committee, where its members have so far managed to agree on the following worth mentioning wording for the household exemption: "by a natural person (...) in the course of (...) exclusively personal or household activity. This exemption also shall apply to a publication of personal data where it can be reasonably expected that it will be only be accessed by a limited number of persons" (2013:11, 61; 2013b:4).

The rational for LIBE's suggested wording is that the proposed Regulation "should not apply to processing of personal data by a natural person, which are exclusively personal, family-related, or domestic, such as correspondence and the holding of addresses or a private sale and without any connection with a professional or commercial activity." Apparently, although LIBE omits from Article 2(2)(d) any specific reference to "gainful interest", it acknowledges that excluding from its scope activities with "professional / commercial" purpose is in fact the underlying rationale. In addition, it essentially agrees with idea of incorporating the CJEU's ratio, however, it suggests an alternative wording to the ones presented above, the latter focusing on the circumstances where the household exemption would apply, by making reference to access "by a limited number of persons", contrary to the circumstances where it shall not, i.e. when the data is accessible by an indefinite number of people (as inter alia EDPS proposed).

Given that LIBE's suggestion is at the time of writing the one to be brought before the EP's plenary session for a final vote, before the inter-institutional negotiations with the Council commence, it worth to pay a closer look. By conducting a literal interpretation of the suggested wording we conclude that it prima facie comprises two situations when the household exemption shall apply: The first one refers to the case where a natural person's act is conducted in the course of exclusively personal or household activity. The "second", appears to be an additional and independent case, in view of the wording "also shall apply"; although, the author's intention could have merely been to explain and analyze the scope of the previous sentence. In any circumstance, what appears to be a "second" case provides for three requirements that must be met in order for it to apply: (a) the personal data must be published, (b) there must be an expectation that there will be limited access to the said personal data 
("access by a limited number of persons") and (c) the expectation in question must be reasonable. Here, LIBE introduces an objective reasonableness test by which a court would have to assess the nature and the particular circumstances surrounding the publication of the personal data to conclude whether it provides limited access to third parties. In this regard, to exclude the application of the exemption, there would be no need to provide additional evidence that the said personal data has indeed been accessed by an indefinite number of people. The only thing required to show in this case is that a reasonable person would expect that under those circumstances this would indeed be the case.

In our view, LIBE's wording, although provides some guidance on how the criterion of "unlimited access" shall be applied, it does not resolve the practical difficulties mentioned above at paragraph 3(b) in relation to the Linqvist decision. In fact, it is the inability of such sole criterion to cover all possible situations that has allowed alternative wording options to emerge.

The main alternative view argues for the non-decisiveness of the unlimited access criterion, i.e. that it should not determine per se whether the exemption shall apply or not. Instead, such criterion should be treated only as one of the several factors to be considered in assessing a given case, by taking into account the related rights of the concerned parties, in particular the freedom of expression (EP, 2012:33). The following argument made by the Art. $29 \mathrm{WP}$ is in our opinion reflecting the gravity of this view: "making information available to the world at large should be an important consideration when assessing whether or not processing is being done of personal purposes. However, this should not in itself be considered determinative. [...We] need to think though the many consequences - in terms of competing rights as well as logictics - of the possibility of bringing hundreds of millions of social network users many of whom will have part of their profile open to anyone - and bloggers for example - within the scope of data protection law"(2013:9). In this light, it is submitted that this criterion should only comprise part of the Regulation's Recital 15 and not be included in the strict wording of Article 2(2)(d), as we will discuss below.

\section{(d) Beyond Normativity: Conciseness and Guidance}

The critical presentation of the abovementioned three suggested criteria (otherwise limitations) to the household exemption has shown that each of them suffers alone from specific defects. For each of the proposed wordings, we have been able to: (a) identify situations where a natural person would be treated unfairly either because the criterion applied is deemed to result in too broad or too narrow application of the exemption and/or (b) identify significant ambiguity in the wording, which results in failing to effectively succeed its purpose, if not creating further complications.

These concerns have led us to consider whether the option of maintaining a rather flexible and broad wording in the normative part of the Regulation, that would capture all instances, without, at the same time, excluding or including more than the ones actually intended, might be of assistance in this respect. We acknowledge that such proposal appears prima facie to bring us backwards to the Directive's current wording, which seemingly we have been trying to reform throughout this paper. Indeed, this apparent impression is partly true. However, as it will be shown, any 
potential deficiency or vagueness caused by the generality of Article 2(2)(d) would be outweighed, in this respect, by the addition of several criteria in the non-normative part, in the form of non-decisive factors that would be taken into account in determining the application of the household exemption in each case.

This approach has so far found strong support in the Art. 29WP's recent opinion earlier this year, where it argued for the preservation of the current wording of Article $3(2)$ of the Directive (with a minor replacement of the phrase "of a purely" with the equivalent "of its own exclusively") (2013:10). Approaching it from another perspective, the Working Party opinioned for omitting the EC's proposed "gainful interest" criterion and maintaining a flexible but admittedly vague wording as explained above. But that's not all. What could arguably be missing from Article $2(2)(d)$, the Working Party believes it should be incorporated exclusively in Recital 15 of the proposed Regulation. To put it simply, since it appears that we are unable to provide for a sole criterion within Article 2(2)(d) (or even a small list of those) that would decisively provide a clear cut solution for each case, without causing unjust outcomes, the only realistically practical solution would be to provide a longer list of criteria that would function more as guides rather than switches. Such guides would be considered by a court or national competent authority in a collective manner and not individually, by taking into consideration the particular facts of each case and the potential conflicting rights of the concerned parties.

How such perspective can be applied in practice is illustrated in the Working Party's opinion, which we shall now turn to consider in more detail. First, the Working Party provides in its suggested Recital 15 the general foundation upon which the household exemption shall apply, i.e. "to processing of personal data by a natural person, which is exclusively personal or domestic, such as correspondence, the holding of addresses of personal contacts or the use of social network sites that is outside the pursuit of a commercial or professional objective". Then, having marked the general context, it further proceeds to define four criteria to be used in determining whether a processing falls within the personal/household exemption, namely: (a) potential dissemination of personal data to an indefinite number of persons rather than to a limited community of friends or family members; (b) the nature of the relationship between the person posting certain data and the person to which the posted information refers to; i.e.whether the personal data is about individuals who have no personal or household relationship with the person posting; (c) whether the scale and frequency of the processing of personal data suggests professional or full-time activity and (d) whether there is evidence of a number of individuals acting together in a collective and organised manner.

Remarkably, the negotiations within the Council, at the time of writing, seem to be in favor of partially adopting the above mentioned perspective. Although we are not in a position to conclude whether this outcome is a result of conscious choice or due to the member states' inability to reach a consensus with regard to including a sole or more criteria in the normative part, we note the Presidency's remarks that Article 2(2)(d) was re-drafted "with a view to reaching a broadly acceptable solution"(Council: 10227/13:4). 
More specifically, the latest compromise text published by the Irish Presidency on the EC's original proposal (Council: 10227/13:8,37) suggests the following wording for Article 2(2)(d): "by a natural person in the course of a personal or household activity;" We note that the criterion of gainful interest and the reference to "exclusivity" contained in the original EC's proposal was omitted, which according to the Presidency's own words "gave rise to interpretation difficulties and controversy".

Unfortunately, the Council's proposal for the respective Recital 15 is not as rich as the one analysed above by the Art. 29WP, given that it remains to a great extent, along the lines of the EC's proposal with an addition worth noting, namely a general reference to "social networking and on-line activities".

Inevitably, a number of questions still remain unanswered, illustrating the challenges of endorsing such approach: When is person considered to use SNS as a platform to advance commercial, political or charitable goals? Concomitantly, when a large number of contacts become too high to be acceptable to the regulator? What does knowing or being in a relationship with someone in the virtual world mean? (EC, 2010:7) A preliminary answer to these questions could be that: (a) it might not be useful to provide a theoretical and abstract response which, although it could prima facie be easily applied uniformly, however, it would remain unrelated to the specific facts of each case, thus potentially leading to unfair judicial decisions and (b) all the above mentioned criteria should be given collectively proportionate weight in balancing the rights of the concerned parties.

Assuming such perspective comes into force, it would be the initial role of the national courts and competent authorities to conduct the respective assessment, based on the facts brought before them. Admittedly, the data protection reform in question aims inter alia to integrate the differentiated data protection laws currently applied within the EU member states; however, considering the various data protection and privacy traditions among Europe, it not unlikely that this might be a long process. In the event that such proposal becomes law, we would expect, at the early stage that national authorities will give different weight to the provided criteria, which would then perhaps result in a less uniform application of the household exemption between member states. Such controversies caused by the domestic differentiated approaches would, however, be finally solved by the CJEU in the form of preliminary rulings following references from national courts. Eventually, a set of CJEU pilot decisions would provide the appropriate guidance on the interpretation and application of Article 2(2)(d) to which all national court and authorities would have to comply. The potential option of having the EC or other specialized bodies such as EDPS and Art. 29WP occasionally, issuing guidelines, recommendations and best practices to ensure consistent application of the Regulation by the national Data Protection authorities would certainly limit any differentiated application of the said provisions among member states (Council 16525/1/12:6). In our view, this admittedly long term but well tested cooperation between the CJEU, EC and national courts and authorities would provide for an effective application of Article 2(2)(d).

\section{Conclusion}


The household exemption, as is currently provided in the Directive 95/46/EC, lacks the desired and necessary clarity in determining when and how the processing of certain data on behalf of a person shall fall under its scope, particularly when the processing act takes place in Web 2.0 environment. The CJEU's guidance in this respect, and in particular the Linqvist decision, does not solve the fundamental defects of Article 3(2) of the Directive and at the same time leaves a number of questions unanswered.

The processing of personal data within Web 2.0 technologies illustrates the interrelation between the applicability of household exemption and the definition of data controller. The users' increasing processing of personal data within SNS and the wide use of UGC results in individuals assuming the parallel roles of data controller and data subject, thus blurring the tension between the two concepts.

Reforming the household exemption proves to be a key area of dispute in the course of the ongoing negotiations on the EU data protection reform. The major tension lies on the selection of criteria, if any, which would be expressly mentioned in the normative part of the proposed Regulation. This is due to the fact that they shall in principle determine whether a processing act shall be regarded as belonging to a user's private life or not. At the present stage, the two institutions, equally involved in the legislative process, namely the Council and the EP, have both decided to amend the EC's original draft, each reaching to different proposals for the wording of what would be Article 2(2)(d) of the proposed Regulation. On the one hand, EP's LIBE committee, seems to be in favor of incorporating the ratio of Linqvist decision, as a criterion in applying the household exemption which refers to the situations where the processed data can be accessed by an indefinite number of people. The Council, on the other, is, so far, in favor of adopting a broad wording, equivalent to the one provided by the current Directive, without however containing any further significant guidance, which is in our opinion an essential defect.

Our analysis has shown that the inclusion of one or more determinative criteria in the normative part of the Regulation, although would prima facie lead to a more uniform application of the exemption, in fact, it is likely that would eventually cause either too broad or too limited application of the exemption, thus resulting to unjust outcomes. In this light, we argue that perhaps the most appropriate and practically efficient option would be to incorporate a broad wording at the Article 2(2)(d) and add further non-determinative criteria at the non-normative part, namely Recital 15 of the proposed Regulation. The application of the said criteria should be conducted in a collective manner and the balance of the respective interests and rights of the concerned parties would be succeeded by taking into consideration the particular facts of the case. This solution arms a judge or competent authority with a list of nondeterminative criteria to be used as a toolbox, in assessing whether certain processing falls under the scope of the proposed Regulation, rather than forcing an abstract ticking-the-box exercise, which would disregard the diversity of cases that can arise in the virtual world and in particular in Web 2.0 environment.

In other words, we argue that the vast variety of users' online activities, particularly the ones that involve UGC and participation in SNS, prevent the EU legislator from sufficiently providing for a clear-cut definition of "private conduct" (as opposed to 
activity done in public), thus, leading us to conclude that a fair, efficient and practical solution would only be achieved if the matter is left to be subsequently determined on case by case basis, by national courts and competent authorities and eventually the CJEU. Such long process might result to the initial fragmentation of the interpretation of proposed Regulation's scope, at least in the short term, before a homogenous application of the proposed exemption is achieved.

\section{References}

\section{Primary Sources}

Article 29 Data Protection Working Party (2009) 'The Future of Privacy. Joint Contribution to the Consultation of the European Commission on the legal framework for the fundamental right to protection of personal data', WP 168 (1.12.2009).

- - (2010) 'Opinion 1/2010 on the concepts of "controller" and "processor", WP 169 (16.02.2010).

- - (2013) 'Proposals for Amendments regarding exemption for personal or household activities', Annex 2 to Statement of the Working Party on current discussions regarding the data protection reform package (27.02.2013).

C-101/01 Bodil Lindqvist v Åklagarkammaren i Jönköping [2003] ECR I-12971.

C-73/07 Satamedia [2008] ECR I-9831.

Committee on Civil Liberties, Justice and Home Affairs (2013) Draft Report on the proposal for a regulation of the European Parliament and of the Council ... (Rapporteur: Jan Philipp Albrecht), 16.01.2013.

- - (2013b) Compromise amendments on Articles 1-29 to the Draft Report on the proposal for a regulation of the European Parliament and of the Council ... (Rapporteur: Jan Philipp Albrecht), 21.10.2013.

Council of the European Union, Presidency Note to the Council (2013), 10227/13, Interinstitutional File: 2012/0011 (COD), Brussels 31.05.2013.

- - Presidency Note to the Council, 10227/13, Interinstitutional File: 2012/0011 (COD), Brussels 31.05.2013.

- - Presidency Note to the Council (2012), 16525/1/12, REV 1, Interinstitutional File: 2012/0011 (COD), Brussels, 03.12.2012.

- - Addendum to Presidency Note to the Council (2013), 10227/13, Interinstitutional File: 2012/0011 (COD), Brussels 31.05.2013.

Directive 95/46/EC of the IEuropean Parliament and of the Council of 24 October 1995 on the protection of individuals with regard to the processing of personal data and on the free movement of such data, Official Journal L 281, 23/11/1995.

European Commission (2012), Proposal for a Regulation of the European Parliament and of the Council on the protection of individuals with regard to the processing of personal data and on the free movement of such data (General Data Protection Regulation), Brussels 25.01.2012, COM(2012) 11 final.

- - (2010) 'Comparative Study on Different Approaches to New Privacy Challenges, in particular in the Light of Technological Developments', Working Paper No. 2: Data protection laws in the EU: The difficulties in 
meeting the challenges posed by global social and technical developments (Douwe Korff), 20.01.2010.

European Parliament (2012) DG for Internal Policies, Policy Department A: Economic and Scientific Policy, Reforming the Data Protection Package Study'.

Opinion of the Committee on the Internal Market and Consumer Protection for the Committee on Civil Liberties, Justice and Home Affairs on the proposal for a regulation of the European Parliament and of the Council ... (Rapporteur: Lara Comi), 2012/0011(COD), 28.01.2013.

Opinion of the Committee on Legal Affairs for the Committee on Civil Liberties, Justice and Home Affairs on the proposal for a regulation of the European Parliament and of the Council...(Rapporteur: Marielle Gallo), 2012/011(COD), 28.01.2013.

Opinion of the European Data Protection Supervisor on the data protection reform package, 07.03.2012.

\section{Secondary Sources}

BEUC Position Paper, 'Data Protection, Proposal for a Regulation' (2012), X/2012/039, 27.07.2012.

European Digital Rights (EDRi) (2013), Position on the Regulation on the protection of individuals with regard to the processing of personal data and on the free movement of such data (General Data Protection Regulation).

Hunton \& Williams (2012) Executive Briefing Paper on Proposed General Data Protection Regulation.

- - 'Council of the European Union Releases Draft Compromise Text on the Proposed EU Data Protection Regulation', Hunton and Williams LLP, Privacy and Information Security Law Blog, 04.06.2013.

Interactive Advertising Bureau (IAB), 'Recent developments on the Data Protection Regulation', September 2013.

International Working Group on Data Protection in Telecommunications (2008), 'Report and Guidance on Privacy in Social Network Services - "Rome Memorandum"' 43rd meeting, 3-4 March 2008, Rome (Italy).

Garrie D., Wong R. (2010), 'Social Networking: Opening the Floodgates to "Personal Data", Computer and Telecommunications Law Review, 16(6), pp. 167-176.

Giannakaki M., 'The EU Data Protection Directive revised: New challenges and perspectives', 4th International Conference on Information Law, Thessaloniki May 20-21, 2011.

Korff D. (2004) Paper No. 4: The Legal Framework, in: I Brown \& D Korff, Privacy \& Law Enforcement, FIPR study for the UK Information Commissioner.

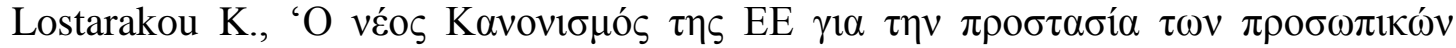
$\delta \varepsilon \delta$ o $\mu \varepsilon ́ v \omega v ; \Delta \mathrm{iMEE}, 3 / 2013$.

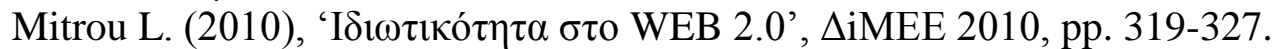

- - (2010b). Privacy challenges and perspectives in Europe. In M. Bottis (ed.), An Information Law for the 21st Century, Athens 2010.

Mitrou L ., Karyda M . ( 2012) 'EU's Data Protection Reform and the right to be forgotten - A legal response to a technological challenge?, 5th International Conference of Information Law and Ethics 2012, Corfu, Greece 29-30 June 2012. 


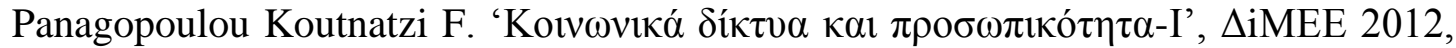
pp. 186-195.

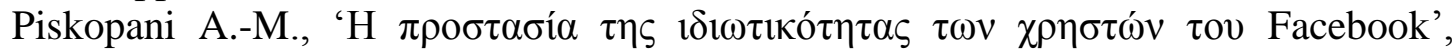
$\triangle$ iMEE 2009:338.

Reding (2009) 'Internet of the future: Europe must be a key player', speech during the meeting Future of the Internet initiative of the Lisbon Council, Brussels, 2 February 2009.

Roth Paul (2010) 'Data Protection Meets 2.0: Two Ships Passing in the Night', The University of New South Wales Law Journal, Volume 33, Issue 2, pp. 532561.

UK Information Commissioner's Office (ICO) (2012), 'Initial analysis of the European Commission's proposals for a revised data protection legislative framework'.

UK's Information Commissioner's Office (ICO) (2013), Proposed new EU General Data Protection Regulation: Article-by-article analysis paper, V1.0 February 2013.

B. Van Alsenoy, J. Ballet, A. Kuczerawy, J. Dumortier (2009) 'Social networks and web 2.0: are users also bound by data protection regulations?', Identity in the information society, vol. 2 , no. 1 .

Warso Zuzanna (2013) 'There's more to it than data protection - Fundamental rights, privacy and the personal/household exemption in the digital age', Computer \& Security Review 29, pp. 491-500.

Wong Rebecca and Savirimuthu Joseph (2008) 'All or nothing: this is the question?: The application of Art. 3(2) Data Protection Directive 95/46/EC to the Internet', John Marshall Journal of Computer and Information Law 25.02.208, pp. 241-266.

Wong Rebecca (2008b), 'Social Networking: Anybody is a Data Controller', available at: SSRN http://ssrn.com/abstract=1271668.

- - (2009), 'Social networking: a conceptual analysis of a data controller', Communications Law, Vol. 14, No. 5, 2009, pp. 142-149. 